Fukushima J. Med. Sci.,

Vol. 64, No. 1, 2018

[Original Article]

\title{
Surgical outcomes of total laparoscopic hysterectomy with 2-dimensional versus 3-dimensional laparoscopic surgical systems
}

\author{
Hiroyuki Yazawa ${ }^{1)}$, Kaoru Takiguchi ${ }^{2)}$, Karin Imaizumi ${ }^{1)}$, Marina Wada ${ }^{3)}$ and Fumihiro Ito ${ }^{1)}$ \\ Department of Obstetrics and Gynecology, Fukushima Red Cross Hospital ${ }^{1}$, Department of Obstetrics \\ and Gynecology, Ohta Nishinouchi Hospital ${ }^{2}$, Department of Obstetrics and Gynecology, Fukushima \\ Medical University ${ }^{3)}$
}

(Received November 20, 2017, accepted February 1, 2018)

\begin{abstract}
Three-dimensional (3D) laparoscopic surgical systems have been developed to account for the lack of depth perception, a known disadvantage of conventional 2-dimensional (2D) laparoscopy. In this study, we retrospectively compared the outcomes of total laparoscopic hysterectomy (TLH) with 3D versus conventional 2D laparoscopy. From November 2014, when we began using a 3D laparoscopic system at our hospital, to December 2015, 47 TLH procedures were performed using a 3D laparoscopic system (3D-TLH). The outcomes of 3D-TLH were compared with the outcomes of TLH using the conventional 2D laparoscopic system (2D-TLH) performed just before the introduction of the 3D system. The 3D-TLH group had a statistically significantly shorter mean operative time than the $2 \mathrm{D}$-TLH group ( $119 \pm 20$ vs. $137 \pm 20 \mathrm{~min}$ ), whereas the mean weight of the resected uterus and mean intraoperative blood loss were not statistically different. When we compared the outcomes for 20 cases in each group, using the same energy sealing device in a short period of time, only mean operative time was statistically different between the 3D-TLH and 2D-TLH groups $(113 \pm 19$ vs. $133 \pm 21 \mathrm{~min})$. During the observation period, there was one occurrence of postoperative peritonitis in the 2D-TLH group and one occurrence of vaginal cuff dehiscence in each group, which was not statistically different. The surgeon and assistant surgeons did not report any symptoms attributable to the 3D imaging system such as dizziness, eyestrain, nausea, and headache. Therefore, we conclude that the 3D laparoscopic system could be used safely and efficiently for TLH.
\end{abstract}

Key words : 3-dimensional laparoscopy, total laparoscopic hysterectomy, surgical outcomes

\section{Introduction}

Laparoscopic surgery has been adopted as a type of minimally invasive surgery to improve quality of life relative to open surgery. Its advantage for patients include smaller surgical incisions, less intraoperative blood loss, less postoperative pain, shorter hospital stay, and earlier resumption of normal activities, especially after gynecological surgery. The lack of depth perception and sense of touch are drawbacks in conventional 2D laparoscopic surgery, that can increase operative time, and surgeon fatigue and stress. Consequently, a 3D lapa- roscopic surgical system was developed to address the lack of depth perception in the 2D laparoscopic system. In November 2014, we began to use a 3D laparoscopic surgical system (VISERA ELITE, ENDOEYE FLEX 3D, OLYMPUS ${ }^{\circledR}$ ) for total laparoscopic hysterectomy (TLH), which is the first-line type of hysterectomy for benign uterine diseases such as leiomyoma or endometriosis in our hospital. In this study, we retrospectively compared the surgical outcomes of TLH with 3D versus 2D laparoscopic surgical systems and investigated the usefulness of the 3D surgical system.

Corresponding author : Hiroyuki Yazawa E-mail : ikyoku12@fukushima-med-jrc.jp

https://www.jstage.jst.go.jp/browse/fms http://www.fmu.ac.jp/home/lib/F-igaku/ 


\section{Objective}

From November 2014 to December 2015, 47 TLHs were performed using the 3D laparoscopic system, including two demonstration cases before the adoption of the 3D system at our hospital. We compared the outcomes of 3D-TLH with the outcomes of 47 cases of $2 \mathrm{D}$-TLH performed just before the adoption of the 3D laparoscopic system.

\section{Material and Methods}

\section{TLH procedure at our hospital (Fig. 1)}

At our hospital, TLH during this study period were as follows. We used 4 trocar ports (one 12 $\mathrm{mm}$ trocar at bottom of the umbilicus for the scope and three $5 \mathrm{~mm}$ trocars in the lower abdomen for manipulation) in a diamond position. The uterus was controlled using a Uterine manipulator ${ }^{\circledR}$ inserted just before the operation began. First, the vesi- couterine peritoneal fold was opened and bladder was mobilized inferiorly with blunt dissection (Fig. 1A). The upper uterine ligaments were then dissected using an energy sealing device LigaSure $\mathrm{V}^{\circledR}$ or Thunderbeat ${ }^{\circledast}$ (Fig. 1B). In all cases, we identified the ureter and uterine arteries in retroperitoneal space. We ligated and cut the uterine arteries (Fig. 1C). The cardinal ligament was ligated and dissected using an energy sealing device (Fig. 1D). The Uterine manipulator ${ }^{\circledR}$ was then removed. The uterovaginal canal was incised using monopolar electrosurgical knife (pure cutting current, 40 watts). Identification of the dissection line was facilitated with a VAGI Pipe ${ }^{\circledast}$ inserted into the vagina (Fig. 1E). The uterus was cut down and extracted transvaginally (Fig. 1F). The vaginal cuff was closed with a laparoscopic one-layer Z-plasty suturing with 0-Vicryl (Fig. 1G). Finally, the retroperitoneum was closed with continuous 2-0 Vicryl sutures (Fig. 1H). Cystoscope was performed and urinary flow from bilateral ureters was confirmed af-

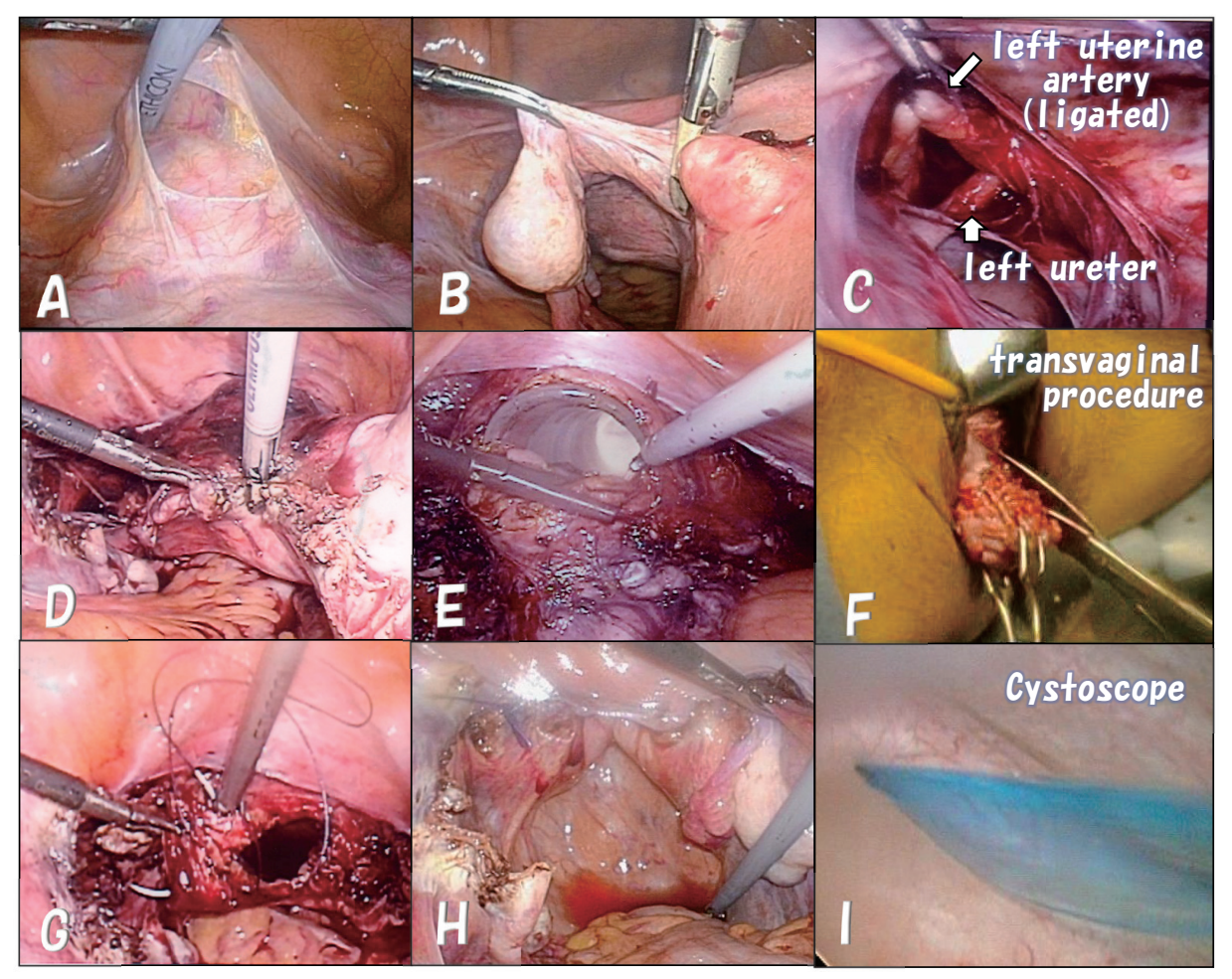

Fig. 1. Total laparoscopic hysterectomy (TLH) procedure for this study.

The vesicouterine peritoneal fold was opened and bladder was mobilized inferiorly with a blunt dissection (1A). The upper uterine ligaments were dissected using LigaSure $\mathrm{V}^{\circledR}$ or Thunderbeat ${ }^{\circledR}$ energy sealing device (1B). The ureters and uterine arteries were identified in retroperitoneal space, and the uterine arteries were ligated and cut (1C). The cardinal ligaments were ligated and dissected using an energy sealing device (1D). The uterovaginal canal was incised by monopolar electrosurgical knife while the dissection line was clarified using VAGI Pipe ${ }^{\circledR}$ inserted into the vagina (1E). The uterus was cut down and extracted transvaginally (1F). The vaginal cuff was closed with laparoscopic one-layer Z-plasty suturing with 0 -Vicryl (1G). Finally, the retroperitoneum was closed with continuous using 2-0 Vicryl sutures $(1 \mathrm{H})$. 
ter the vaginal cuff was sutured (Fig. 1I). All TLHs during this study period were performed by one surgeon.

\section{Comparison of surgical outcomes ;}

We adopted the 3D laparoscopic surgical system in November 2014. By December 2015, 47 cases of 3D-TLH were performed, including two demonstration cases performed before the adoption. Operative time, intraoperative blood loss, weight of the removed uterus, and complication of these $473 \mathrm{D}-$ TLH cases and 47 cases of 2D-TLH performed just before the adoption of the 3D laparoscopic system were compared. We also compared the outcomes of 20 cases in each group, because the study period was so long (approximately 2.5 years) and the sealing devices changed during the study periods. Additionally, we compared the outcomes between the first half (23 cases) and second half (22 cases) of 3DTHL cases.

Statistical analysis was performed using the $\mathrm{t}$ test and chi-square test. A p value $<0.05$ was considered statistically significant.

\section{Results}

1) Surgical methods and number of laparoscopic hysterectomy $(\mathrm{LH})$ procedures in our hospital.

We have been performing LH at our hospital since 2001. Before 2007, all LH procedures consisted of laparoscopically assisted vaginal hysterectomy (LAVH), followed by transmitting laparoscopic hysterectomy [LH(a)]. TLH was introduced gradually starting in 2010, and by 2013 most LH procedures were $\mathrm{TLH}^{1)}$. The surgeon had performed approximately 230 cases of LAVH and LH(a) and 41 cases of TLH at the beginning of this study.

By December 2015, we had performed 135 TLHs $(2 \mathrm{D}+3 \mathrm{D})$. Figure 2 indicates the learning curve by operative time for one surgeon. Although TLH often took over three hours in the early days, the slope of the learning curve decreased after approximately 30 cases, as typically reported. The surgeon was considered to acquire the adequate skills for TLH at the beginning of this study.

\section{2) Comparison of patient backgrounds (Table 1)}

We compared the background of patients who underwent $2 \mathrm{D}$-TLH versus $3 \mathrm{D}$-TLH. Results are shown in Table 1 . There were no significant differences between two groups in factors that could influence TLH outcomes, such as body mass index (BMI) and history of laparotomy (including appendectomy), cesarean sections, vaginal deliveries, complication of endometriosis (endometrial cyst and/or adenomyosis), and concurrent adenectomy.

\section{3) Surgical outcomes}

The surgical outcomes of the 47 2D-TLH cases and 47 3D-TLH cases (red square in Figure 3 ) are shown in Table 2 . The duration of the study period was 16 months for the 2D-TLH group and 14 months for the 3D-TLH group. For the $2 \mathrm{D}-\mathrm{TLH}$ and 3D-TLH groups, the mean weight of the resected uterus was $292 \pm 138 \mathrm{~g}, 273 \pm 138 \mathrm{~g}$, mean intra-

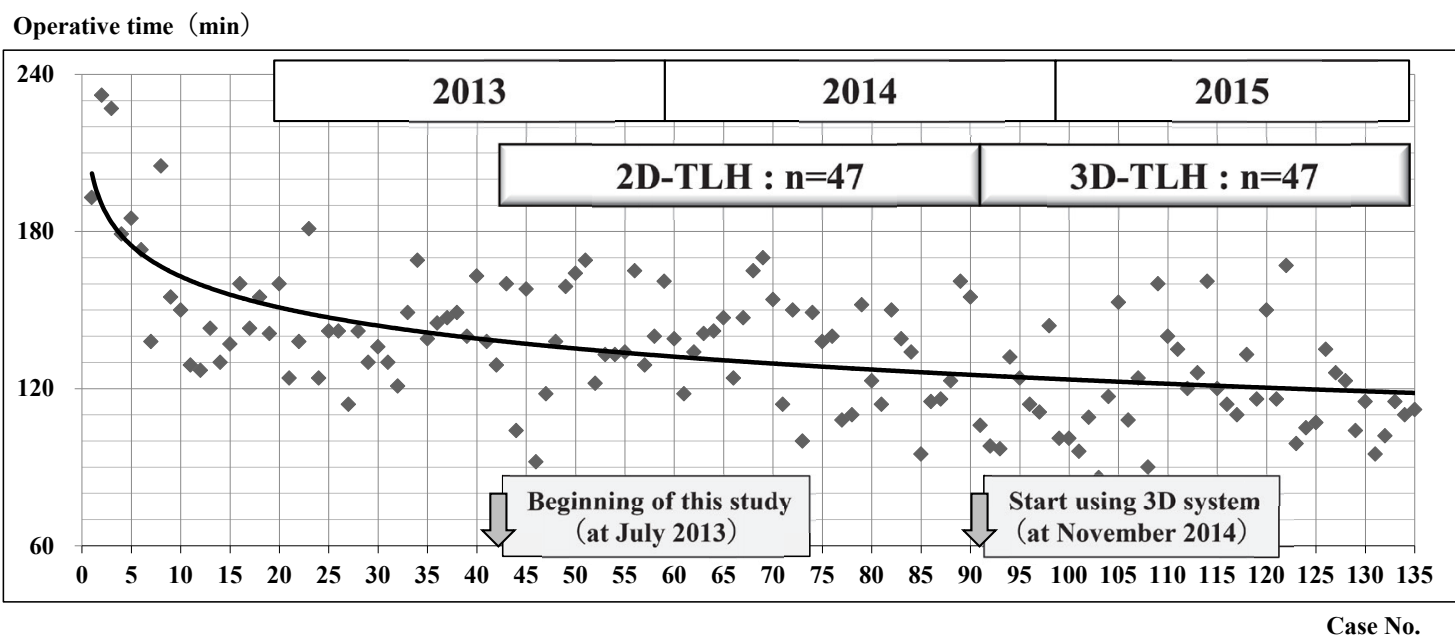

Fig. 2. Learning curve based on operative time for 135 cases of total laparoscopic hysterectomy (TLH) performed by one surgeon until December 2015.

The slope of the learning curve decreased after approximately 30 cases. The surgeon was considered to proficient at TLH before the beginning of this study. 
Table 1. Comparison of the patient background of between two-dimensional total laparoscopic hysterectomy (2D-TLH) and three-dimensional (3D)-TLH groups.

\begin{tabular}{lccc}
\hline & 2D-TLH\# & 3D-TLH\# & p value \\
\hline Cases & 47 & 47 & \\
Age (y) : mean \pm SD & $42.3 \pm 4.1(33-50)$ & $44.7 \pm 3.8(36-51)$ & 0.325 \\
BMI : mean \pm SD & $22.6 \pm 3.3$ & $23.1 \pm 3.6$ & 0.585 \\
With past history of C/S & 5 & 11 & 0.100 \\
$\begin{array}{l}\text { 0 vaginal delivery } \\
\text { (0 gravida+C/S delivery only) }\end{array}$ & 8 & 12 & 0.313 \\
$\begin{array}{l}\text { Past histroy of laparotomy } \\
\text { (including appendectomy) }\end{array}$ & 6 & 11 & 0.180 \\
$\begin{array}{l}\text { With endometriosis } \\
\text { (including chocolate cyst) }\end{array}$ & 3 & 2 & 0.646 \\
$\begin{array}{l}\text { With adenomyosis } \\
\text { With adenectomy }\end{array}$ & 8 & 8 & 1 \\
\hline
\end{tabular}

$\mathrm{SD}=$ standard deviation, $\mathrm{BMI}=$ body mass index, $\mathrm{C} / \mathrm{S}=$ cesarean section \#No statistically significant differences between the $2 \mathrm{D}-\mathrm{TLH}$ and $3 \mathrm{D}-\mathrm{TLH}$ groups were found for all the factors examined.

Table 2. Comparison of the surgical outcomes between the two-dimensional total laparoscopic hysterectomy (2D-TLH) $(\mathrm{n}=47)$ and three-dimensional (3D)-TLH $(n=47)$ groups.

\begin{tabular}{|c|c|c|c|c|c|c|}
\hline Group & No. & Age (y) & $\begin{array}{l}\text { Weight of } \\
\text { uterus }(\mathrm{g})\end{array}$ & $\begin{array}{l}\text { Blood loss } \\
\text { (ml) }\end{array}$ & $\begin{array}{l}\text { Operative } \\
\text { time (min) }\end{array}$ & Complication \\
\hline $\begin{array}{l}\text { 2D } \\
\text { TLH }\end{array}$ & 47 & $\begin{array}{c}42.3 \\
\pm 4.1 \\
(33-50)\end{array}$ & $\begin{array}{c}292 \\
\pm 138 \\
(110-635)\end{array}$ & $\begin{array}{c}192 \\
\pm 174 \\
(0-805)\end{array}$ & $\begin{array}{c}137 \\
\pm 20 \\
(92-170)\end{array}$ & $\begin{array}{c}2 \\
\text { *vaginal cuff } \\
\text { dehiscence } \\
\text { *peritonitis }\end{array}$ \\
\hline $\begin{array}{l}\text { 3D } \\
\text { TLH }\end{array}$ & 47 & $\begin{array}{c}44.7 \\
\pm 3.8 \\
(36-51)\end{array}$ & $\begin{array}{c}273 \\
\pm 138 \\
(90-600)\end{array}$ & $\begin{array}{c}161 \\
\pm 147 \\
(0-680)\end{array}$ & $\begin{array}{c}119 \\
\pm 20 \\
(86-161)\end{array}$ & $\begin{array}{c}1 \\
\text { *vaginal cuff } \\
\text { dehiscence }\end{array}$ \\
\hline $\mathrm{p}$ value & & 0.325 & 0.510 & 0.346 & $<0.05$ & 0.557 \\
\hline
\end{tabular}

The mean operative time was statistically significantly shorter in the $3 \mathrm{D}-\mathrm{TLH}$ group. Other factors were not statistically significantly different between the two groups.

operative blood loss was $193 \pm 174 \mathrm{ml}, 161 \pm 147 \mathrm{ml}$, and mean operative time were $137 \pm 20 \mathrm{~min}, 119 \pm 20$ min, respectively. Compared with the $2 \mathrm{D}-\mathrm{TLH}$ group, the 3D-TLH group had a significantly shorter mean operative time (-18 min), The $3 \mathrm{D}-\mathrm{TLH}$ group had less mean intraoperative blood loss $(-31 \mathrm{ml})$, although this difference was not statistically significant. There was one occurrence of postoperative peritonitis in the 2D-TLH group and one occurrence of vaginal cuff dehiscence in each group ; complication rates were not statistically different.

Surgical outcomes of $202 \mathrm{D}$-TLH cases and 20 3D-TLH cases (blue square in Figure 3 ) are shown in Table 3. The duration of the study period was 6 months in the 2D-TLH group and 7 months in the $3 \mathrm{D}-\mathrm{TLH}$ group. For the $2 \mathrm{D}-\mathrm{TLH}$ and $3 \mathrm{D}-\mathrm{TLH}$ groups, the mean weight of resected uterus was $237 \pm 145 \mathrm{~g}, 251 \pm 140 \mathrm{~g}$, mean intraoperative blood loss was $184 \pm 149 \mathrm{ml}, 162 \pm 170 \mathrm{ml}$, and mean operative time was $133 \pm 21 \mathrm{~min}, 113 \pm 19 \mathrm{~min}$, respectively. Compared with the 2D-TLH group, the 3DTLH group had a significantly shorter mean operative time (-20 min). The 3D-TLH group had less intraoperative blood loss $(-22 \mathrm{ml})$, although this difference was not statistically significant. There was one occurrence of vaginal cuff dehiscence in each group.

After excluding the two demonstration cases, the surgical outcomes of the 23 cases in the first half of the study period and 22 cases in the second half (green square in Figure 3) were compared (Table 4). The duration of the study periods was 7 months in each group. For the first and second halves of the 3D-TLH group, the mean weight of the resected uterus was $262 \pm 148 \mathrm{~g}$ and $278 \pm 127 \mathrm{~g}$, mean intraoperative blood loss was $196 \pm 167 \mathrm{ml}$ and $131 \pm 123$ 


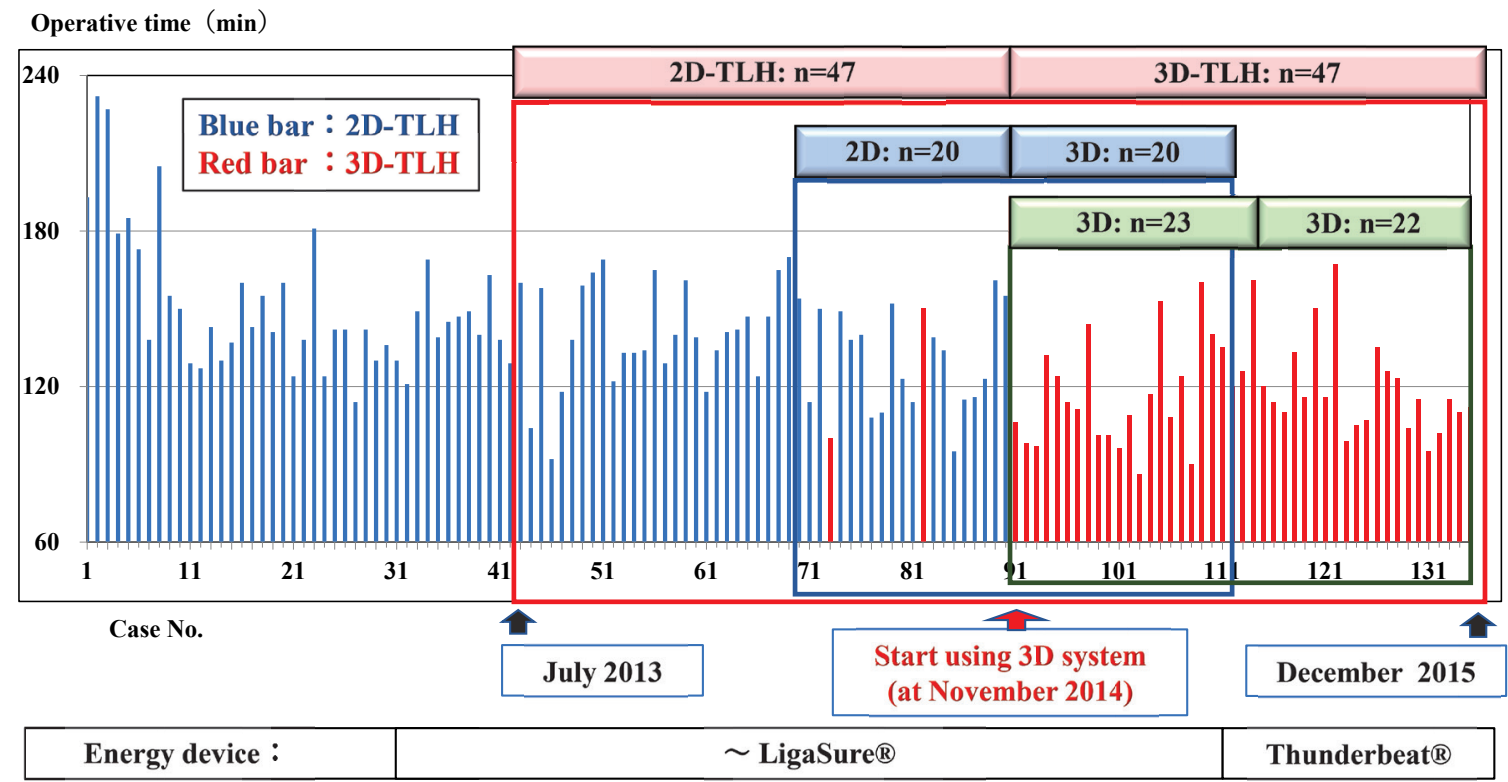

Fig. 3. Operation time for each case and the three comparison groups in this study.

(1) The red rectangle indicates the comparison between 47 cases of two-dimensional total laparoscopic hysterectomy(2D-TLH) and 47 cases of three-dimensional (3D)-TLH.

(2) The blue rectangle indicates the comparison between 20 cases of $2 \mathrm{D}-\mathrm{TLH}$ and 20 cases of 3D-TLH.

(3) The green rectangle indicates the comparison between the first 23 cases and subsequent 22 cases of 3D-TLH.

Table 3. Comparison of the surgical outcomes between two-dimensional total laparoscopic hysterectomy $(2 \mathrm{D}-\mathrm{TLH})(\mathrm{n}=20)$ and three-dimensional $(3 \mathrm{D})-\mathrm{TLH}$ $(n=20)$ sub-groups.

\begin{tabular}{|c|c|c|c|c|c|c|}
\hline Group & No. & Age (y) & $\begin{array}{l}\text { Weight of } \\
\text { uterus }(g)\end{array}$ & $\begin{array}{l}\text { Blood loss } \\
\quad(\mathrm{ml})\end{array}$ & $\begin{array}{l}\text { Operative } \\
\text { time (min.) }\end{array}$ & $\begin{array}{l}\text { Complica- } \\
\text { tions }\end{array}$ \\
\hline $\begin{array}{l}\text { 2D } \\
\text { TLH }\end{array}$ & 20 & $\begin{array}{c}42.3 \\
\pm 3.6 \\
(38-50)\end{array}$ & $\begin{array}{c}237 \\
\pm 145 \\
(110-600)\end{array}$ & $\begin{array}{c}184 \\
\pm 149 \\
(20-615)\end{array}$ & $\begin{array}{c}133 \\
\pm 21 \\
(95-170)\end{array}$ & $\begin{array}{c}2 \\
\text { *vaginal cuff } \\
\text { dehiscence } \\
\text { *peritonitis }\end{array}$ \\
\hline $\begin{array}{l}\text { 3D } \\
\text { TLH }\end{array}$ & 20 & $\begin{array}{c}44.7 \\
\pm 4.4 \\
(36-51)\end{array}$ & $\begin{array}{c}251 \\
\pm 140 \\
(90-520)\end{array}$ & $\begin{array}{c}162 \\
\pm 170 \\
(0-680)\end{array}$ & $\begin{array}{c}113 \\
\pm 19 \\
(86-153)\end{array}$ & $\begin{array}{c}1 \\
\text { *vaginal cuff } \\
\text { dehiscence }\end{array}$ \\
\hline $\mathrm{p}$ value & & 0.413 & 0.626 & 0.642 & $<0.05$ & 0.731 \\
\hline
\end{tabular}

The mean operative time was statistically significantly shorter in 3D-TLH group. Other factors were not statistically significantly different between the two groups.

$\mathrm{ml}$, and mean operative time was $117 \pm 20 \mathrm{~min}$, $120 \pm 19$ min, respectively. There were no statistically significant differences between the two groups.

Regarding complications, there were two instances of vaginal cuff dehiscence $(2.1 \%)$ and one instance of postoperative peritonitis $(1.0 \%)$ during this study period, which might be a little higher than the usual incidence. By December 2016, we had performed 188 TLHs with three instances of vaginal cuff dehiscence $(1.6 \%)$, one instance of postoperative peritonitis $(0.5 \%)$, and no injuries to the intestines, urinary tract, or other organs.

\section{Discussion}

Laparoscopy has been widely adopted as a type of minimally invasive surgery. It offers great advantages compared with open surgery, such as less blood loss, less postoperative pain, shorter hospital stay, earlier resumption of normal activities, and fewer complications such as postoperative adhesions, ileus, and infections, as well cosmetic benefits $^{1-3)}$. It is also possible to reliably perform precise operations in a magnified operative field by bringing the scope closer to the targets of surgery. Consequently, the quality of laparoscopic surgery is 
Table 4. Comparison of the surgical outcomes between the first 23 cases and subsequent 22 cases in the three-dimensional total laparoscopic hysterectomy (3D-TLH) group.

\begin{tabular}{|c|c|c|c|c|c|}
\hline $\begin{array}{l}\text { Case } \\
\text { No. }\end{array}$ & Age (y) & $\begin{array}{l}\text { Weight of } \\
\text { uterus }(\mathrm{g})\end{array}$ & $\begin{array}{l}\text { Blood loss } \\
\quad(\mathrm{ml})\end{array}$ & $\begin{array}{l}\text { Operative } \\
\text { time (min.) }\end{array}$ & Complications \\
\hline $\begin{array}{c}\text { First } \\
23\end{array}$ & $\begin{array}{c}44.6 \\
\pm 3.9 \\
(36-51)\end{array}$ & $\begin{array}{c}262 \\
\pm 148 \\
(90-650)\end{array}$ & $\begin{array}{c}196 \\
\pm 167 \\
(0-680)\end{array}$ & $\begin{array}{c}117 \\
\pm 20 \\
(86-160)\end{array}$ & $\begin{array}{c}1 \\
\text { *vaginal cuff } \\
\text { dehiscence }\end{array}$ \\
\hline $\begin{array}{l}\text { Second } \\
22\end{array}$ & $\begin{array}{c}44.7 \\
\pm 4.4 \\
(40-51)\end{array}$ & $\begin{array}{c}278 \\
\pm 127 \\
(100-600)\end{array}$ & $\begin{array}{c}131 \\
\pm 123 \\
(0-435)\end{array}$ & $\begin{array}{c}120 \\
\pm 19 \\
(95-167)\end{array}$ & 0 \\
\hline $\mathrm{p}$ value & 0.447 & 0.363 & 0.410 & 0.629 & 0.323 \\
\hline
\end{tabular}

None of the factors were not statistically significantly different between the first and second half of 3D-TLH cases.

higher and patients have a better QOL. However, lack of depth perception and sense of touch are drawbacks of conventional laparoscopy that may burden surgeons with fatigue or stress. A 3D surgical system was developed to solve the disadvantage of lack of depth perception with conventional laparoscopy. Safer and more precise surgery may be possible with depth awareness and improved resolution of the operative field with the 3D imaging system.

Since the first report by Becker et al. in 1993 ${ }^{4)}$ that a 3D display might improve laparoscopic skills in the dry laboratory setting, many studies have been performed to demonstrate the value of 3D imaging for laparoscopic training or surgery ${ }^{5-8)}$. Although the differences between 2D and 3D imaging system were not recognized shortly after introduction of 3D systems, recent studies have suggested that $3 \mathrm{D}$ systems are useful as the quality of $3 \mathrm{D}$ imaging improved. A 3D laparoscopic system might be beneficial during the initial learning process, especially for nonadvanced laparoscopists using the box trainer. It is expected to shorten the learning curve in surgical performance, ${ }^{5,6}$.

In 2011, a Cochrane Review comparing the clinical outcomes of 2D and 3D laparoscopic systems demonstrated no significant differences between groups receiving 2D versus 3D laparoscopic cholecystectomy $^{7)}$. Subsequently, Bilgen $e t$ al. reported that a 3D laparoscopic system with a new 3D imaging system shortened the operative time for cholecystectomy ${ }^{8)}$.

On the other hand, dizziness, eyestrain, nausea, and headache have been reported as adverse effects of 3D laparoscopy for surgeons ${ }^{5)}$. In 3D movies, such effects were associated with individual susceptibility, the movie length, and view angle ${ }^{9}$. During 3D laparoscopic surgery, novices experienced dizziness more frequently than experienced laparosco- pists ; however, it was mild and decreased over time, so it might not be clinically significant ${ }^{10)}$. In our experience, we did not identify any adverse effects in the surgeon, assistant surgeons, assistant nurses, and anesthetists, so the occurrence of these effects seemed to be rare. Approximately $2 \%$ of the general population is estimated to have no stereovision and $15 \%$ are estimated to have some degree of stereodeficiency. Therefore, the benefits of $3 \mathrm{D}$ imaging may be limited for some surgeons ${ }^{11)}$.

In the field of gynecologic surgery, Fanfani et al. recently reported the results of an randomized control trial (RCT) comparing the outcomes of 3D versus 2D laparoscopic hysterectomy and lymphadenectomy by both novice $(<10$ procedures) and expert ( $>50$ procedures) surgeons in 90 patients of endometrial or cervical cancer ${ }^{11)}$. Although surgical outcomes such as operative time and estimated blood loss for the entire procedure, and postoperative complications were similar in both groups, operative time for hysterectomy performed by expert surgeons, operative time for pelvic lymphadenectomy performed by novice surgeons, and the estimated blood loss during lymphadenectomy showed statistically significant benefits in the 3D group compared with the $2 \mathrm{D}$ group. The authors concluded that a 3D system could provide important benefits, especially in reducing operative time for expert surgeons and enhancing surgical precision for novice surgeons ${ }^{11}$.

In this study, we retrospectively compared the surgical outcomes of TLH performed using a 2D versus 3D laparoscopic system by one surgeon. We found that the mean operative time for 3D-TLH was statistically significantly shorter. The study patients were cases 42 to 135 of this surgeon's experience with TLH. Since the surgeon was not necessarily an expert in laparoscopic surgery, it was 
possible that improvements in his surgical skills with TLH occurred with increase surgical experience, whether using $2 \mathrm{D}$ or $3 \mathrm{D}$ system. To minimize the potential bias associate with surgical experience, we conducted a similar comparative subanalysis between 20 cases in each group during a shorter period (from case 69 to 108). Since similar results were also obtained, we concluded that the 3D laparoscopic system could be useful for the surgeon. The surgeon felt that the 3D imaging system improved visual resolution of the operative field and facilitated procedures such as suturing and closing. The author actually felt the usefulness of 3D laparoscopic system, especially during the opening of the retroperitoneal space, isolation of the ureters and uterine arteries, treatment of the cardinal ligaments, and suturing of vaginal cuff or retroperitonroeum in $3 \mathrm{D}-\mathrm{TLH}$.

The mean intraoperative blood loss (MIBL) in the 2D-TLH and 3D-TLH groups were $193 \mathrm{ml}$ and $161 \mathrm{ml}$ respectively. The $3 \mathrm{D}-\mathrm{TLH}$ group tend to have less MIBL than the 2D-TLH group, although the difference between the two groups was not statistically significant. In the 2D-TLH group, there were three cases with over $500 \mathrm{ml}$ blood loss $(615 \mathrm{ml}, 730 \mathrm{ml}, 805 \mathrm{ml})$, so we observed that MIBL with 2D-TLH might be higher than that of standard blood loss of TLH. Conversely, there were five cases with less than $50 \mathrm{ml}$ blood loss in the 2D-TLH group and 12 cases in the 3D-TLH group, so we considered the possibility that blood loss could be reduced by the depth perception provided by the 3D laparoscopic system.

Vaginal cuff dehiscence is an important known postoperative complication of TLH. Its incidence was reported as $0.6 \%(4 / 677)$ by Hada et al. ${ }^{12)}$ and $1.14 \%$ (9/789) by Agdi et al ${ }^{13)}$ Generally, the incidence of vaginal cuff dehiscence with the TLH was higher than with abdominal hysterectomy. Excessive use of power source or electrocautery (which results in poor vascularity), suturing methods (suture strength or thickness in the vaginal wall), and wound infection were listed as the possible causes of vaginal cuff dehiscence in $\mathrm{TLH}^{12)}$. There were two cases of vaginal cuff dehiscence during our study period $(2.1 \%)$. This was higher than the previous reported incidence, but we could not identify the actual causes. By December 2017, we had performed 245 cases of TLH with three occurrences of vaginal cuff dehiscence $(1.2 \%)$. After the most recent case occurred in December 2014, we had not experienced it in over 150 cases over 3 years. We expect that the incidence will decrease to the general level with more TLH experience. Including other complications, it is difficult to conclude from this study whether the 3D laparoscopic system the cause of a lower complication rate. However, the author feels that the improved visual resolution of the operative field with the 3D imaging system might be one of the factors associated with a decrease in the occurrence of complications.

To demonstrate the usefulness of the 3D imaging system for TLH, it is necessary to compare the outcomes of $2 \mathrm{D}$-TLH and 3D-TLH groups using prospective RCT. We once considered conducting an RCT, but concluded it was too difficult to do so. In our hospital, we had publicized the introduction of a 3D surgical system as "one of the newest surgical systems for safer and more precise surgery". One reason for not being able to conduct an RCT was the anticipated difficulties in obtaining consent from patients to be randomized to the 2D system instead of the 3D system. Another reason was that the surgeon (author) himself had strongly felt that the 3D laparoscopic system was more useful by the end of this study.

At our hospital, we use $5 \mathrm{~mm}$ flexible scope in the laparoscopic surgeries for ovarian tumor resection or myomectomy because we have adopted a "reduced port surgery" for these procedures. The 3D laparoscopic surgical system has been limited to only TLH performed by four trocar ports. Although it may be technologically difficult to obtain clear 3D moving image with a $5 \mathrm{~mm}$ scope at this time, we expect that a finer 3D camera system will be developed in the near future that can be used for all laparoscopic surgeries, because 3D laparoscopic system is useful for performing more precise and safer surgery.

\section{Conflict of interest}

There are no conflicts of interest of relevant to this article.

\section{References}

1. Yazawa H, Sasaki M, Ito F. Efforts to expand the indications for laparoscopic hysterectomy in our department ; The effect of introducing of TLH on patients, current status, and future prospects. (in Japanese) Fukushima Med J, 65 : 170-182, 2015.

2. Aarts JW, Nieboe TE, Johnson N, et al. Surgical approach to hysterectomy for benign gynecological disease. Cochrane Database Syst Rev, Aug 12(8) : CD003677, 2015. 
3. Ridgeway B, Falcone T. Innovations in minimally invasive hysterectomy. Clin Obstet Gynecol, 47 : 83-94, 2014.

4. Becker H, Melzer MJ, Reddy PK. 3-D video techniques in endoscopic surgery. Endosc Surg Allied Technol, 1 : 40-46, 1933.

5. Ko JKY, Li RHW, Cheung VYT. Two-dimensional versus three-dimensional laparoscopy : evaluation of physicians' performance and preference using a pelvic trainer. J Minim Invasiv Gynecol, 22 : 421-427, 2015.

6. Nagendran M, Gurusamy KS, Aggarwal R, et al. Virtual reality training for surgical trainees in laparoscopic surgery. Cochrane Database Syst Rev, Aug 27(8) : CD006575, 2013.

7. Gurusamy KS, Sahay S, Davidson BR : Three dimensional versus two-dimensional imaging for laparoscopic cholecystectomy. Cochrane Database Syst Rev, Jan 19(1) : CD006882, 2011.

8. Bilgen K, Ustum M, Karakahya M, et al. Comparison of $3 \mathrm{D}$ imaging an 2D imaging for performance time of laparoscopic cholecystectomy. MSurg Laparosc Endosc Percutan Tdch, 32 : 180-183,
2013.

9. Solimini AG. Are there side effects to watching $3 \mathrm{D}$ movies? A prospective crossover observational study on visually induced motion sickness. PLoS One, 8 : e56160, 2013.

10. Kong $\mathrm{SH}, \mathrm{Oh} \mathrm{BM}$, Yoon $\mathrm{H}$, et al. Comparison of two- and three-dimensional camera systems in laparoscopic performance : a novel 3D system with one camera. Surg Endosc, 24 : 1132-1143, 2010.

11. Fanfani F, Rossitto C, Restaino S, et al. How technology can impact surgeon performance: A randomized trial comparing 3-dimensional versus 2-dimensional laparoscopy in gynecology oncology. Minim Invasiv Gynecol, 23 : 810-817, 2016.

12. Hada T, Ando M, Kanao H, et al. Vaginal cuff dehiscence after total laparoscopic hysterectomy : Exmination on 677 cases. Asian J Endosc Surg, 4 : 20-25, 2011.

13. Agdi M, Al-Ghafri W, Antolin R, et al. Vaginavault dehiscence after hysterectomy. J Minim Invasiv Gynecol, 16 : 313-317, 2009. 